\title{
GCU
}

Glasgow Caledonian

University

University for the Common Good

\section{Cultural competence as a technology of whiteness: race and responsibilisation in Scottish health and social care}

Russell, Lani

Published in:

International Journal of Human Rights in Healthcare

DOI:

10.1108/IJHRH-06-2020-0048

Publication date:

2021

Document Version

Author accepted manuscript

Link to publication in ResearchOnline

Citation for published version (Harvard):

Russell, L 2021, 'Cultural competence as a technology of whiteness: race and responsibilisation in Scottish health and social care: race and responsibilisation in Scottish health and social care', International Journal of Human Rights in Healthcare, vol. 14, no. 1, pp. 74-86. https://doi.org/10.1108/lJHRH-06-2020-0048

\section{General rights}

Copyright and moral rights for the publications made accessible in the public portal are retained by the authors and/or other copyright owners and it is a condition of accessing publications that users recognise and abide by the legal requirements associated with these rights.

Take down policy

If you believe that this document breaches copyright please view our takedown policy at https://edshare.gcu.ac.uk/id/eprint/5179 for details of how to contact us. 


\title{
Cultural competence as a technology of whiteness: race and responsibilisation in Scottish health and social care
}

\begin{abstract}
Purpose - The purpose of this paper is to explore and extend understanding of the concept of cultural competence in relation to whiteness, particularly the implications of this link in the context of heightened concerns about safety and risk connected with the responsibilisation of health and social care.
\end{abstract}

Design/methodology/approach - The paper is a critical review of academic literature about cultural competence in health and social care, focussing on Scotland. The discussion develops understandings of cultural competence in light of important writing about whiteness and draws on recent related research, for example, about racial patterning in relation to disciplinary proceedings.

Findings - Cultural competence is an example of the neoliberal fusion of the ideals of quality and equality. It is a technology of whiteness which may reinforce racial disadvantage especially in the current environment of responsibilisation. Cultural competence is associated with individual responsibility tropes which undermine state-funded welfare provision and re-inscribe traditional inequalities.

Practical implications - The findings reinforce the importance of a focus on the social determinants of health and challenge 'audit' approaches to competence of all kinds, favouring instead the promotion of creativity from 'the margins'.

Originality - This paper brings together several areas of literature, which have perhaps previously not overlapped, in order to identify under-recognised implications of cultural competence in the sector, thus linking the critical discussion to decolonisation and good practice in new ways.

Key words cultural competence, health and social care, race, responsibilisation, whiteness, audit society, neoliberalism, mew managerialism, decolonisation, biopolitics.

Paper type Conceptual paper

\section{Introduction}

The coronavirus pandemic has highlighted gross racial health inequalities both in the workforce generally, and in the health and social care workforce specifically, in the UK (Kamal, 2020). The pandemic also adds one more urgent dimension to a wider global crisis manifest in interrelated symptoms like climate change and the international plight of refugees. The case for fundamental change at all levels of our 
systems has never been stronger. This paper considers one of the ways in which attempts have been made to redress racial inequality in the UK health and social care system. The research uses a critique of 'cultural competence' as a springboard to explore how fundamental change might look in the context of the everyday management of health and social care workplaces.

Whilst reviewing literature for a textbook about the sociology of health, it was observed that racialisation is rarely mentioned in research about the policing of employees in relation to concerns about safety and risk. It was also noted that competence seemed to be framed as unproblematic in the widespread promotion of cultural competence to redress racial inequality in this area. These observations suggested a conceptual inconsistency. Exploring that inconsistency is the rationale for this research. The paper considers the concept of cultural competence and its relationship to the ways race gets remade in neoliberal contexts. Observations are made specifically in relation to health and social care provision in Scotland. The article explores the intersections of research about racial inequality and a body of work which criticises new managerialism, the audit society and 'responsibilisation' in the public sector. The significance of the research lies in its new synthesis of discussions that tend not to be connected.

\section{Methodology and argument}

The method used in this paper is a critical review and synthesis of existing research about cultural competence which draws on research about race and neoliberalism, about new managerialism and about the situation of racialised [1] staff in health and social care. Using a theoretical framework inspired by David Theo Goldberg, Michel Foucault and others, it considers what cultural competence means and how the idea operates in the particular setting of a 'risk and responsibilisation' environment. The 
argument was developed on the basis of a wide and deep literature search conducted over several years. To ensure reliability and validity, key social science databases were systematically searched using the key terms 'cultural competence', 'health' and 'social care', considering international scholarship but with a sharper focus in relation to the UK and Scotland. Backwards and forward searches and a thorough survey of key reviews and contributions were conducted to build a comprehensive and up-to-date understanding of how cultural competence is being used and criticised. Secondarily, as the subject was interrogated, more specific searches were conducted, for example, to identify new and relevant publications in the area, and research regarding racial patterns in disciplinary proceedings. The survey of relevant scholarly writing using the concept of whiteness built on and extended the author's own previous research.

The distinctive contribution made in this article is an argument about the ways that cultural competence works to re-inscribe race and class in this context. The narrative goes on to suggest that defiance of day-to-day micromanagement of health and social care must be an important aspect of decolonial practice in the workplace, not only in relation to 'cultural competence' but 'competencies' of all kinds. Lifeenhancing practice, by this argument, needs to come from the margins and resist codification and capture. The 'tick box' approach has been much criticised and this research contributes to the search for much needed alternatives.

\section{Structure}

The discussion begins with a brief overview of the concept of cultural competence in Scottish health and social care in an attempt to situate the research in a concrete context from the outset. The following sections outline criticisms of the idea of 
cultural competence, discussing it in relation to whiteness, governmentality and 'soft' equalities practice in the public sector. Cultural competence is thus connected with the issue of competence in general and then explored in relation to the current intense focus on individual responsibility for safety mistakes in health and social care. These are issues which have been little discussed perhaps partly because there are so many people working in health and social care whose racialisation has not prevented them from being recognised as competent at the highest levels of these systems. However, this success should not distract from the discrimination experienced at every level by racialised people. The argument made in this paper is that race today is a contested but persistent frame for explaining incompetence, as evidenced in recent research about the over-representation of racialised people in disciplinary proceedings. The final section suggests that projects to instil cultural competence would be better framed as projects attempting to achieve decolonisation. Such an approach would focus on exposing and challenging structural disadvantage and the symbolic violence associated with it. This approach would involve acknowledging and promoting unconventional competencies associated with life on the social margins.

\section{Cultural competence and its profile in Scottish health and social care}

One of the most cited definitions describes cultural competence as:

... a set of congruent behaviours, attitudes and policies that come together in a system, agency or professional and enable that system, agency or

professional to work effectively in cross-cultural situations (Cross, 1988, p.1).

More recently, cultural competence or 'interculturality' has been recognised as an emergent form of cultural capital (Phipps, 2010, p.4). Cultural competence has even been described as 'the key competence par excellence in a globalised world' 
(Seukwa, 2007, p.13). There is now an enormous body of international literature about the concept across many fields, including social work, transcultural psychiatry and mental health. Cultural competence is also increasingly institutionalised. In health care, the concept has been reified by inclusion as an accreditation standard in the US and Canada and as legislation in New Zealand, and its use is pervasive in policy documents and medical education in Australia (Paul et al., 2014). Whilst this influence has not been replicated in the UK to the same extent, cultural competence has steadily achieved increasing prominence in NHS training, especially in health care (Barn and Das, 2016). Despite Scotland having independent responsibility for health and social care in the UK since devolution in 1999, key UK trends in the management of health and social care are features of Scottish systems, which include new managerialism (Fraser, 2017), asset-based approaches to community development (ABCD) (MacLeod and Emejulu, 2014) and increasingly, cultural competence. The concept was embedded with the policy document, $A$ Fairer Healthier Scotland (2013) as part of a focus on safe, effective and person-centred care, and is now a priority for education and workforce development planning (NES, 2017).

The focus on cultural competence in Scotland can be viewed as the achievement of individuals and organisations dedicated to making Scottish health and social care provision more responsive to the needs of racialised people. The National Resource Centre for Ethnic Minority Health (NRCEMH) 2002-2008, for example, was an expert working group set up partly to assist NHS boards to achieve racial equality and cultural competence. This group framed cultural competence as an attribute which could be promoted at both an individual and organisational level. Raj Bhopal, a leader in the field and previously Chair of the NRCEMH, has used the term as 
synonymous with 'cultural sensitivity' (Bhopal, 2012). The idea has also been used increasingly to refer to a targeted approach to health and social care. From this perspective, a culturally competent health and social care system is one that can address particular health patterns associated with 'cultural or religious values that either promote or hinder behavioural change' and 'accommodate varying degrees of cultural identification' (Netto et al., 2010, p. 248). Baradaran et al. (2006), in their survey of diabetes provision for Minority Ethnic Groups in Scottish Local Health Care Cooperatives (LHCC), identify access to interpreters, recording of cultural/religious requirements, culturally appropriate dietetic counselling and appropriate health information as indicators of cultural competence. Cultural competence is thus a banner for a variety of projects aimed at improving service for racialised people in Scotland. Perhaps central to these is the relatively uncontroversial idea that the ability of people to understand and support 'ethnic others' can be developed and thus foster more equal treatment.

It is important to recognise that these initiatives are being instituted in a country in which $84 \%$ identify as 'white Scottish', with most of the remaining $16 \%$ also from 'white' groups (ONS, 2011). In relation to training, cultural competence is thus very much, though not exclusively, aimed at this white majority. At the same time, the concept is often described in training literature as a means for redressing not just racial but other inequalities, to achieve a genuinely universal and respectful standard of care that can account for and accommodate difference.

\section{Criticisms of cultural competence}

Drevdahl et al. (2008) made the important argument that cultural competence, with its focus on individual change, deflects attention from the need to address the 
broader social determinants of health as a basis for redressing health inequalities.

This issue has been key to World Health Organisation efforts to reform governance. In addition, a consistent criticism of cultural competence programmes internationally, voiced perhaps especially within the field of social work, is that they are essentialising and can result in the reinforcement of stereotypes. Drevdahl et al. (2008) suggest that this approach assumes it is possible to simplify and manage culture. The result is the development of inventories of healthcare beliefs of particular racialised groups which reinforce or indeed construct essentialised ideas about racialised people. Such approaches are not what is needed to achieve nondiscriminatory social care. As Drevdahl et al. $(2008$, p.20) indicated:

In the end, it is much easier for nurses to use checklists for certain ethnic and racial groups than to engage in meaningful, albeit difficult and uncomfortable conversations, especially given time and language limitations.

Canadian Occupational Therapist Brenda Beagan (2018) notes that the blunt 'laundry list' approach has fallen out of favour in the past decade but that it is still 'routine to encourage clinicians to gain more knowledge of ethnic and racialized minority groups' (p.125). Cultural competence is essentialising because it works to reinforce traditional positionings of clients and experts. David Hollinsworth, criticising the concept in social work practice, specifically emphasises its association with white privilege. He argues for an approach which:

...moves from casting cultural differences as 'other' or alterity to an unexamined and normative "whiteness" to recognition of our intercultural world where all identities are formed and work within interpenetrating and inter-referential social and cultural domains (Hollinsworth, 2013, p.7). 
These criticisms of cultural competence are consistent with the ideas of thinkers such as Michel Foucault and David Theo Goldberg. Foucault (2003) argued that the modern management of populations he called 'biopolitics' is in essence a racial project. He defined race broadly as referring to the biological purity of a people. Within racial studies, David Theo Goldberg has expanded the Foucauldian lens to explore features of neoliberalism, notably the persistent 'burying' of race. He argues that under neoliberalism race as a concept continues to structure society and individual lives in profound ways but must always be pushed down and denied because it undermines the now limping project of legitimising the free market. Neoliberalism is thus associated with the denial of race and a renewed and more strident insistence on the neutrality, the essential racelessness, of the still-dominant white colonial core. The more abstract whiteness becomes, the more it needs to be imposed and the more work that is needed to paper over the cracks. Race and social difference generally have thus been formally, but unequally, included in public life, yet left free to rampage privately. Social difference, in this view, is a threat to neoliberal projects which valorise 'mixture', framing difference as a product of, and tool for, the free market, yet simultaneously denying racial inequality, which is relegated to history. The neoliberal era, then, is marked by increasingly aggressive measures to assert an over-riding neutrality and control the ever-present symptoms of social difference which continue to be expressed (Goldberg, 2009; Hunter, 2015). This background is important for helping to situate cultural competence in relation to whiteness and neoliberalism.

\section{New managerialism and cultural competence as a technology of whiteness}

Foucault and Goldberg's ideas have been used to think about public sector promotion of equality and diversity in the context of new managerialism. This is 
relevant for thinking about cultural competence which can be characterised as a managerial 'soft equalities' approach. The sociologist Shona Hunter (2015), exploring public sector managerialism in the context of whiteness, provides a useful lens for thinking about the implications of cultural competence, and for thinking about the entanglements that arise in relation to this concept specifically at a time when concerns about responsibility, risk, and safety are increasingly salient. Hunter argues, following Goldberg (and Paul Gilroy), that diversity management and other soft approaches to equality are melancholic managerial techniques associated with the ongoing and painful confrontation of the neoliberal state with its colonial and hence racial past and present. Neoliberal whiteness is characterised by its 'benevolent outreach'. It is presented as offering inclusion to the excluded and by this means becomes 'civilisational and untouchable in its promotion of the general 'good' (Hunter, 2015, p.12). Citing Michael Power (1994,1999) she notes that new managerialism, portrayed as neutral and technical, brings in '... an elaborate apparatus of auditing methods rooted in the tradition of financial risk analysis' aimed at producing behavioural change in individuals 'at a distance' (Hunter, 2015, p.13). These audit technologies have become technologies of the self, constituting individuals as 'responsibilised and accountable subjects' (Davies and Bansel, 2010, p.9, cited in Hunter, 2015, p.13).

This optic is relevant to criticisms of cultural competence but also raises questions about the promotion of competence in general. Hunter notes that the ideals of quality and equality have now become fused. In the twenty-first century, 'contemporary practices of liberal whiteness' are associated with 'flexibility, diversity, communication and holistic care as well as economic efficiency and accountability' (Hunter, 2010, p.453) and are involved with new discursive ideals of professional 
success and good practice. Hunter notes that within the British National Health Service (NHS), New Labour modernisation from 1997 onwards linked the achievement of equality with efficiency and effectiveness in such a way that equality 'was viewed as directly linked to improving the quality of patient care' (Hunter, 2010, p.455). In this context, ideas about quality and diversity, along with community cohesion and human rights, 'operate as powerful euphemisms for attempts to resolve racialised and ethnicised difference', collapsing and eliding social disadvantages and serving to 'reinstate whiteness as an unmarked general (Hunter, 2015, p.11).

Tascon and Gatwiri (2020) make the important point that cultural competence programmes are forms of condescension because the white professional is the assumed beneficiary, 'positioned to consume the Other: to know them in proprietary fashion' (Tascon and Gatwiri, 2020, p.8). However, it is important to be clear also that whiteness is a concept that helps us understand how race is remade and that its connection with individual people, racialised or not, is complicated. Whilst individuals can be racist or ally themselves with racism, this does not mean that those promoting and delivering cultural competence, many of whom are not positioned as white, are 'agents of whiteness'. Discourses and practices of whiteness have a life and trajectory of their own beyond the utterances and actions of individuals. As Goldberg has argued, 'whiteness' and 'blackness' are not simply racial identifications, but 'represent class positions: the former of relative privilege, the latter of disprivilege' (Goldberg, 2014, p.33).

If cultural competence is approached in this way, it can be usefully seen, with other 'soft equalities' measures, as a technology of whiteness and thus, a form of governmentality. Cultural competence has provided a new means for the marking of 
lives to be promoted and nurtured as against others judged unworthy of the same. The public face of cultural competence is the elevation of individuals who can work across 'cultures', pushing against racial and ethnic markers. Yet in practice cultural competence instead works to re-inscribe race and class. It might be seen as an example of a technology designed to produce a certain kind of self from which profit can be extracted, as described by Beverley Skeggs (Skeggs, 2004, p. 21, citing Rose, 1989, 1992). An ability to translate across 'cultures' is a feature of that self but translation does not overcome, rather refreshes, 'culture'. As Anna Tsing suggests, learning another culture is an enterprise which "both bridges and maintains difference' (Tsing, 2019, p.112, citing Satsuka, 2015).

The issue of social class must be emphasised here. As Beverley Skeggs noted, whilst for the middle class, cultural omnivorousness has become a means of distinction, for others culture is something one is forced to perform as 'a "natural" part of being' (Skeggs, 2004, p.77). To say that cultural competence is a technology of whiteness is to say that rather than unsettling pre-existing power relations, cultural competence provides yet more cover for systems that remain profoundly white.

Cultural competence works with other technologies of whiteness to shore up the cultural core, reinforcing white expertise and the positioning of the core as the wellspring of civilised values. It does this even where those working to foster cultural competence are themselves racialised. It works in this way as part of a wider assemblage of technologies associated with the fused ideals of quality and equality, including technologies of audit which work to constitute individuals as responsibilised subjects.

\section{Made and kept 'incompetent': responsibilisation and race}


The deserved recognition of the achievements of highly qualified and proficient migrants and people of colour in health and social care at all levels in the UK does not negate the historical and contemporary reality that competence is raced and that being read as culturally inadequate continues to be a hidden injury of race. Since at least the nineteenth century, competence has been constituted in the image of the colonial centre and (mis)representations of the (in)competence of the colonised work as part of that constitution. In relation to the health sector, as Hunter (2015) notes, Britain's nineteenth century 'civilizing mission' was an essential aspect of the story of professional nursing, the image of Florence Nightingale simultaneously a model for colonial 'development' and crucial to the self-image of white British nurses. As such, conceptions about what it means to be competent and incompetent reflect, express and work to buttress existing power relations and constitute whiteness. If it is considered that to appear competent is fundamental to the performance of modern personhood and civility, this is injury indeed.

In the twenty-first century race also continues to be manifest in global structural inequality, including ongoing patterns of disadvantage in the global health and social care workforce within and across countries (Wrede, 2010). That inequality is shored up culturally by ongoing reference to ideas about competence. In the era of neoliberalism, one way that whiteness is reworked (Winddance Twine and Gallagher, 2008) is by reading racialised people as incompetent, whilst simultaneously denying the raciality of that reading. This can be seen, for example, in relation to the Roma people in Europe. As Silvia Rodríguez Maeso (2014) notes, European integration policies situate Roma poverty and deprivation in relation to Roma inadequacy, specifically a lack of 'acquired socio-professional competences', 
in a move which furthers stigmatisation and forecloses discussion about structures that 'govern minorities and protect privilege' (Maeso, 2014, p.62).

Competence is also a subject of intense focus in twenty-first century health and social care where competency-based education is now an international feature of the sector (Beagan, 2018, citing Wear, 2008). In the UK in particular this culture has come to be associated with intense scrutiny of staff in relation to safety, fuelled by negative press about poor quality nursing and iatrogenesis (Traynor et al., 2013). The issue of staff incompetence is an important modality of responsibilisation. This term refers to the focus on individual action linked to the neoliberal retreat from the obligations of the welfare state (Kelly, 2001). The rise of responsibilisation reflects increased anxiety about risk and the associated perception of a need to police and prevent health care safety mistakes at an individual level.

In this environment where employees struggle daily to place themselves on the better end of a competence/incompetence spectrum, the ongoing salience of race means that it will inevitably be implicated in the way those struggles are experienced and understood. Little seems to have been written exploring this particular entanglement of race and responsibilisation, but a growing body of evidence suggests that racialised people in the UK are more vulnerable, all other things being equal, to being cast as incompetent. Roger Kline $(2014$, p.4) found that racialised (or 'BAME' for 'Black and Minority Ethnic') staff in London's NHS workforce, whilst representing two out of every five NHS staff, are more likely to face disciplinary action or be reported to professional regulators. This reflects and extends other injuries: racialised staff are found disproportionately in lower grades, underrepresented in senior management, treated less favourably in recruitment, promotion, incremental and performance awards and bonus payments, and are more 
likely to experience bullying and harassment (ibid) [2]. Sehmi's doctoral dissertation on the over-representation of BAME employees in the disciplinary process in a National Health Service Trust (2015) shows that BAME staff whose attitudes and behaviours did not conform to accepted norms were those most likely to be involved in disciplinaries, even where this non-conformity did not reflect a breach in performance standards. In this extract of an interview with an adult nurse in NHS England, Archibong et al. (2019, p.4) highlight problems of 'misreading':

I think one of the key things from my experience is attitudes and perspectives on assertiveness and aggressive ... I'm quite a vocal person and I will speak my mind. If I feel something is not right I will say, and it can be taken that I'm being aggressive but to me, I'm being assertive. I've actually asked or voiced my opinion on something, and I think that's cropped up time and time again and that is something that is the springboard so to speak that actually widens the net to ... disciplinary actions because they are deemed as aggressive.

Race situates racialised people to their disadvantage. The symbolic violence of being read as 'aggressive' in this instance is one example. An alternative reading, which identifies 'race' in such competence-related encounters, is a controversial and embattled narrative in a 'post-racial' era where this kind of account can provoke accusations of 'reverse racism' (Goldberg, 2009; Harries, 2014).

Yet there is clearly abundant basis for such a reading, especially where lines of class division are transparently racial. For example, ethnographic research by Bach and colleagues (2009) in hospital wards in England graphically demonstrated how the intense focus on a myriad of rules to ensure safety in primary health care may impact negatively on both patient care and the working lives of racialised health workers. Interviews conducted by Bach et al. demonstrated professional boundary work between nurses and Health Care Assistants (HCAs). HCAs are an example of a growing body of health workers disproportionately drawn from racialised groups 
and increasingly tasked with the most intimate health and social care work (see also Kline, 2014). Staff interviewed for this project referenced issues of qualification and competence that clearly link to inequalities in the workforce with HCAs expressing resentment about their role of doing the 'dirty' work: 'we are the ones that wipe the bum'. Behind conversations about ostensibly neutral technical issues such as skills, training and responsibility, issues of racial, class and gender positioning loom large. Tabloid newspaper coverage also illustrates how public anxiety about safety, and the competence and responsibility of nurses in particular, can easily fall into predictable racial grooves, as evidenced in headlines like 'How did Filipino serial killer get a job in the NHS? Fears 'devil' nurse who murdered two patients and poisoned 20 more faked his qualifications to work in a UK hospital' (Daily Mail, 18 May 2015). In the current context, health and social care workers are increasingly vulnerable to criminalisation. This trend is consistent with historic characterisations of poor and classed people as dangerously inept, whether at home, in their personal lives or at work, and such portrayals continue to be refigured. For racialised people living on or close to the margins, the racial logics of competence provide a crude added inflection to this symbolic violence.

It should be emphasised that this connection between racial positioning and competence discourse is complicated, fluid, and contested. As implied above, racialised casting is complicated by intersectionality which can result in fluidity in relation to issues of competence. An example is provided by Catto et al. (2010) who surveyed newspaper coverage about the impact of Central and Eastern European migration on the Scottish health service 2004-2008. The authors give an account of the dismissal of two Polish consultants in the Highlands of Scotland following media coverage which purported to expose inadequate UK experience, 'substandard levels 
of clinical skill and poor English ability' (Catto et al., 2010, p.771). However, this coverage dramatically shifted as details of a shortage of national consultants emerged, morphing under contest into a story of two internationally experienced professionals unjustly targeted and inadequately supported by managers (ibid). This example illustrates the potential for new 'competence stories' that defy predictable grooves. Yet it also highlights a precarity of working life for racial and ethnic outsiders who run the risk of slipping in and out of 'competence'.

This discussion adds a new complexity to the issue of cultural competence. Often, cultural competence training is promoted precisely as a means to ensure management awareness and sensitivity about racial bias. It is argued by Sehmi (2015) and Archibong et al. (2019), for example, that a key factor in the inequality of punishment for poor practice is a lack of cultural competence at management level. However, as argued above, cultural competence only serves to reiterate essentialised cultural difference. As Sehmi's own research (2015) demonstrates, the biopolitical lens ensures that even where racialised people have been recruited to disciplinary panels in an attempt to counter-balance this dynamic, they are at risk of being positioned in essentialising ways. Marcia, a BME nurse, reveals:

I have been asked explicitly to sit on a panel because I am black. I don't know whether you have met $X$, she has been asked explicitly saying 'We want you on the panel because you're black...' But I was there to assess whether this lady from Namibia... I was asked to help with the competency. Interestingly when we went to do the competency assessment, she didn't even relate to me, she didn't even want to talk to me... I do not know what the Namibian culture is. We share the same shade of skin, that's almost about all... it was bandied there in the hearing, 'You are here to provide a cultural perspective.' I mean for a nurse not to be able to understand the medication procedures is not a cultural issue, it's a competence issue... (Sehmi, 2015, p.177) 
This example highlights the limitations of cultural competence as an answer to racism. These limitations exist because both culture and competence are already racialised terrain. This wider context of racialisation and competence is also important to take into account when considering these issues in the case of Scotland.

\section{Cultural competence and race in Scotland}

In Scotland, the promotion of cultural competence should be understood as part of a broader post-racial plan aimed at putting to rest any conflicts about Scotland's colonial past. Scotland has embraced civic nationhood and promoted migration as a means to build a declining population. This is not presented as a change of heart but the desire of a people only ever reluctantly a part of the British Empire.

Consequently, the Scottish approach to racial inequality within its own borders has tended to be 'no problem here' (Davidson et al., 2018) on the basis that Scottish nationalism, unlike English nationalism, is liberal and progressive. In this, Scotland suffers from amnesia about its colonial past and thus denies or underplays the continued salience of race within its borders. Instead, the discourse is of a sophisticated, generous and inclusive people whose experiences of highland closures and unequal treatment at the hands of the English have resulted in a natural empathy for marginal others. Despite growing awareness about Scotland's historical relationship with slavery (see for example Linpää in Davidson et al., 2018) and evidence of the limits of Scottish anti-racism (Curtice and Montagu, 2018) a tradition and habit of imagining the nation as a cradle of civilisation and a model for all kinds of good practice internationally is still influential. 
The example of the Polish consultants in the account above highlights that positive narratives about racial outsiders are one part of the field of discursive possibility in Scotland but shows also how easily migrants and racialised people can be cast as 'not up to our standard'. The country's unresolved reckoning with the colonial past is reflected in approaches to cultural competence which still tend to treat 'culture' as something that others have, with culturally competent health and social care workers seen as providing a 'meeting in the middle' about different health beliefs to help newcomers to adapt to 'a new set of social norms and behaviour' (Quickfall, 2014, p.252). The clear implication is that, like the Roma in Maeso's study (2014), cultural outsiders are to be remade, not the systems that position them to their disadvantage. In this context targeted support for particular communities also risks failing to confront the ongoing structural inequalities which continue to remake and recharge racial difference. As Thackrah and Thompson (2013) suggest, the fluidity of the concept of 'culture' at the heart of cultural competence also makes it difficult to assess the value of such targeted approaches for redressing those inequalities.

\section{Discussion and practical implications}

The usefulness of the idea of whiteness is that it draws attention to ways the colonial core is continually reconstituted as the heart of civilisation. People are thus positioned in relation to that cultural centre. Neoliberalism works to keep covering its tracks, refusing race and individualising inequality to hide the growing chasm between the rich and powerful and the rest. Lack of whiteness or insufficient exposure to the ways of the supposedly civilised is routinely used to frame racialised people, in places like the UK, as backward and dangerous, prone to crime and prey to foreign-based 'radical' ideologies. This analysis notes another, quieter, but no less 
damaging register of racialisation that involves a pernicious story of inadequate employees prone to procedural error.

A number of authors have suggested alternatives to cultural competence. Cultural humility, for example, has been put forward as a way to move beyond awareness of cultural difference towards critical reflexivity and analysis of power imbalance (see Beagan, 2018; Tascon and Gatwiri, 2020). However, this still falls within the framework of a focus on the retraining of individuals and competency-based education. In everyday life, discourses of race as biological and cultural difference live on alongside ideas of competence as neutral and non-racial, making competence an unstable, contested and dangerous field for many racialised people.

The call for self-improvement, of which cultural competence is but one example, is a symptom of a social order facing a profound crisis of legitimacy. For this social order to change, the focus on improving selves to achieve 'best practice' needs to be challenged, and for that, unorthodox stories and experiences of health and social care that come from the margins need to be revalued and brought forward. As Amin has argued, in relation to the management of migration, creativity in the workplace and the integration of the stranger are the product of situated engagement and the 'irregular beat of practice', a beat not captured by 'the language of attribute or measure - so much trust, social capital or cohesion, or so much supply of skills and people' (Amin, 2012, p.57). In addition to being a distraction from resource issues, there are good reasons to question the hegemonic assumption that good practice can only be ensured by generic procedures. It is not necessary to romanticise the 'incompetent' to imagine a move away from such rigid measures. In health and social care as in fields such as music, art and science, intuitive 'craft' approaches to competence exist and may even work unofficially to smooth out the gaps associated 
with the tick box approach. A recognition that there is more than one way to conduct any activity well, against the flattening out of differences in both subjects and objects associated with generic procedures, would be helpful. Caring for another being involves empathy and imagination. These qualities are not fostered but actually stymied by the 'audit' approach (Sennett, 2009).

Seen from this perspective, the task of challenging micro-managerial techniques in the workplace, including but not limited to the promotion of cultural competence, can be seen as part of the project of decolonisation. The idea of culturally unfit populations, which invokes both race and class, needs to be thoroughly defeated. To push in a different direction would involve promoting 'competencies' that are associated with being positioned outside the mainstream. An example of this is identified by Henry Seukwa (2007) who itemised a list of competencies he observed had been fostered amongst German refugees as a result of their experience of being refugees. From his interviews he identified key elements of what he describes as the Habitus of the Art of Survival including 'The Art of Pushing on Despite Uncertainty', 'Social Contacts as a (Re-) stabilising Factor on Days of Despair', 'The Art of Planning a Future in Absolute Uncertainty' and 'Subordinating Dreams to Plans'. This approach is helpful because it repositions marginalised people as competent, knowledgeable models from whom others can learn. It is also consistent with one of Linda Tuwahi Smith's 25 principles for decolonising methodologies, which is to celebrate survival (Tuwahi-Smith, 2012). Such methodologies offer a badly needed way forward, not only for racialised people but for societies in dire need of epistemological diversity (de Sousa Santos, 2014).

\section{Further research}


Ethnographic research would be valuable to follow the route of cultural competence talk as it makes its way in particular health and social care workplaces. This research can ask questions such as: who excels in the 'culturally competent' workforce and what is the process by which their expertise is established? Such research could explore who is being found wanting and how patterns of supposed inadequacy fit with neoliberal power structures. It would interrogate how self-improvement projects hail people into place, whether staff or clients, and ask what new civilising missions are being undertaken. This research could explore the ways in which competence is marshalled in recuperations of whiteness and identify capacities that are hidden or not seen because of the focus on fixing supposed cultural weaknesses. Such an approach would be relevant not only for racialised people but for those situated to their disadvantage by other inequalities such as social class, gender, sexuality and disability. More proactively, participatory action research could work to explore and promote 'creative irresponsibility' or rebellious approaches to practice by health and social care practitioners, seeking to uncover unrecognised approaches to care amongst the 'less skilled' to offer new ways forward beyond the sterile and exhausting framework of audit and 'best practice'.

\section{Conclusion}

In this paper evidence has been presented in support of the argument that cultural competence is an example of the neoliberal fusion of the ideals of quality and equality. Further, the argument is made that cultural competence is best understood as a technique of whiteness that may result in disadvantage for some racialised people and migrants, especially in the context of a focus on client safety and the accountability of individual health and social care staff. The implication of this argument is that efforts to promote cultural competence cannot be understood 
separate from individual responsibility tropes which work not only to undermine state-funded welfare provision but also to reinforce the unmarked cultural centre as neutral and, paradoxically, as the cradle and caretaker of civilisation. In Scotland, with its many legacies of colonial slavery, this is a problem that poses particular challenges. To push in a new direction, practitioners need to support, nurture and promote diverse teams and encounters to foster 'craft' approaches as an alternative to the current focus on the measurement of the competence of individuals, cultural or otherwise, and as part of the project of shifting attention to the key issue of redressing social inequality. The intense focus on the surveillance of individual responsibility in the context of under-resourcing represents an obstacle not only to racial equality but to safety, good health and wellbeing for all.

[1] The term 'racialised people' is used throughout this paper in preference to BME or Black and Minority Ethnic people to emphasise the social and historical imposition of raciality.

[2] Whether a similar trend is occurring in Scotland is difficult to assess, due to inadequate data collection by public sector bodies (see for example, CRER, 2014).

\section{References}

Amin, A. (2012), Land of Strangers, Polity Press, Cambridge. ISBN: 9780745652184

Archibong, U., et al. (2019), 'Disproportionality in NHS disciplinary proceedings', British Journal of Healthcare Management, Vol. 25 No. 4, pp.1-7. DOI: 10.12968/bjhc.2018.0062 
Bach, S. et al. (2009), 'Nursing a grievance? The role of healthcare assistants in a modernised National Health Service', Gender, Work and Organisation, Vol. 19 No. 2, pp.205-223. DOI: 10.1111/j.1468-0432.2009.00502.x

Baradaran, H.R. et al. (2006), 'Scottish survey of diabetes services for minority ethnic groups', BMC Health Services Research, Vol. 9 No. 6, p.130. DOI: $10.1186 / 1472-6963-6-130$

Barn, R. and Das, C. (2016), 'Family group conferences and cultural competence in social work', The British Journal of Social Work, Vol. 46 No. 4, pp. 942-959. DOI: 10.1093/bjsw/bcu105

Beagan, B.L. (2018), 'Chapter Six: a critique of cultural competence: assumptions, limitations, and alternatives' in Frisby, C., and O'Donohue, W., (Ed.s) Cultural Competence in Applied Psychology, Springer, Cham, pp. 123-138. DOI: 10.1007/978-3-319-78997-2_6

Bhopal, R.S. (2012), 'The quest for culturally sensitive health-care systems in Scotland: insights for a multi-ethnic Europe', Journal of Public Health, Vol. 34 No. 1, pp.5-11. DOI: 10.1093/pubmed/fdr094

Catto, A. and Gorman, D. (2010), 'The impact of recent Central and Eastern European migration on the Scottish health service: A study of newspaper coverage 2004-2008', Health and Place, Vol. 16 No. 5, pp.765-775. DOI:

10.1016/j.healthplace.2009.12.006

Coalition for Racial Equality and Rights (CRER) (2014) The State of the Nation: Race and Racism in Scotland. Ethnicity and Employment in Scotland's public sector. Second edition. Vol. 3, CRER, Glasgow 
Cross, T.L. (1988), 'Services to minority populations. Cultural competence continuum', Focal Point, Vol. 3 No. 1, pp.1-4, available at:

http://pathwaysrtc.pdx.edu/pdf/fpF88.pdf (accessed 19 June 2020)

Curtice, J. and Montagu, I. (2018) Do Scotland and England \& Wales have Different Views about Immigration? NatCen Social Research, ScotCen Social Research, Strathclyde, available at: http://natcen.ac.uk/media/1672027/Do-Scotland-andEngland-and-Wales-Have-Different-Views-About-Immigration.pdf (accessed 19 June 2020)

Davidson, N. et al. (2018), No Problem here: Understanding Racism in Scotland, Luath Press, Edinburgh. ISBN: 978-1-912147-30-4

De Sousa Santos, B. (2014), Epistemologies of the South: Justice against Epistemicide, Routledge, Abingdon, Oxon, NY. ISBN: 9781612055459

Drevdahl, D.J. et al. (2008), 'Of goldfish tanks and moonlight tricks. Can cultural competency ameliorate health disparities?', Advances in Nursing Science, Vol. 31 No. 1, pp.13-27. DOI: 10.1097/01.ANS.0000311526.27823.05

Foucault, M. (2003), Society must be Defended, trans. David Macey, Penguin, London. ISBN-13: 978-0-14-027086-0

Fraser, G. (2017), Neoliberalism, New Managerialism and the New Professionalism in Community Development, Doctoral thesis, University of Edinburgh, available at: https://era.ed.ac.uk/handle/1842/25813 (accessed 19 June 2020)

Goldberg, D.T. (2009), The Threat of Race: Reflections on Racial Neoliberalism, Blackwell Manifestos series, Wiley-Blackwell, Malden, MA. ISBN-13: 9780631219682 
Goldberg, D.T. (2014), Sites of Race: Conversations with Susan Searls Giroux, Polity Press, Cambridge. ISBN-13: 978-0-7456-7179-6

Harries, B. (2014), 'We need to talk about race', Sociology, Vol. 48 No. 6, pp.11071122. DOI: $10.1177 / 0038038514521714$

Hollinsworth, D. (2013), 'Forget cultural competence; ask for an autobiography', Social Work Education: the International Journal, Vol. 32 No. 8, pp.1048-1060. DOI: $10.1080 / 02615479.2012 .730513$

Hunter, S. (2015), Power, Politics and the Emotions: Impossible Governance? A GlassHouse Book, Routledge, London. ISBN 9781138685840

Hunter, S. (2010), 'What a white shame: race, gender, and white shame in the relational economy of primary health care organisations in England', Social Politics, Vol. 17 No. 4, pp.450-476. DOI: 10.1093/sp/jxq015

Kamal, M. (14 May 2020), 'Coronavirus statistics lay bare the dire racial inequalities of our society', Opinion, Counterfire, available at:

https://www.counterfire.org/articles/opinion/21199-coronavirus-statistics-lay-bare-thedire-racial-inequalities-of-our-society (accessed 19 June 2020)

Kelly, P. (2001), 'Youth at risk: processes of individualisation and responsibilisation in the risk society', Discourse: Studies in the Cultural Politics of Education, Vol. 22 No. 1, pp.23-33. DOI: 10.1080/01596300120039731

Kline, R. (2014), The "Snowy White Peaks" of the NHS: a Survey of Discrimination in Governance and Leadership and the Potential Impact on Patient Care in London and England, Middlesex University, available at: http://www.england.nhs.uk/wpcontent/uploads/2014/08/edc7-0514.pdf (accessed 19 June 2020) 
MacLeod, M.A. and Emejulu, A. (2014), 'Neoliberalism With a Community Face? A Critical Analysis of Asset-Based Community Development in Scotland', Journal of Community Practice, Vol. 22 No. 4, pp.430-450. DOI:

$10.1080 / 10705422.2014 .959147$

Maeso, S.R. (2014), "'Civilising" the Roma? The depoliticization of (anti-)racism within the politics of integration', Identities, Vol. 22 No. 1, pp.53-70. DOI:

10.1080/1070289X.2014.931234

Netto, G. et al. (2010), 'How can health promotion interventions be adapted for minority ethnic communities? Five principles for guiding the development of behavioural interventions', Health Promotion International, Vol. 25 No. 2, pp.248257. DOI: $10.1093 /$ heapro/daq012

NES (2017), Equality Outcomes and Mainstreaming Report, NHS Education for Scotland, available at:

https://www.nes.scot.nhs.uk/media/3969911/Equality\%200utcomes\%20and\%20Mai nstreaming\%20Report.pdf (accessed 25 June 2020)

Paul, D. et al. (December 2014), 'Cultural competence in medical education: aligning the formal, informal and hidden curricula', Advances in Health Sciences Education, Vol. 19 No. 5, pp.751-758. DOI: 10.1007/s10459-014-9497-5

Phipps, A. (2010), 'Drawing breath: creative elements and their exile from higher education', Arts and Humanities in Higher Education, Vol. 9 No. 1, pp.42-53. DOI: $10.1177 / 1474022209350103$

Quickfall, J. (2014), 'Cultural competence in practice: the example of the community nursing care of asylum applicants in Scotland', Diversity \& Equality in Health and Care, Vol. 11, pp.247-53. DOI: 10.21767/2049-5471.1000013 
Sehmi, H.S. (2015) An Ethnographic Study exploring the Over-representation of Black and Minority Ethnic (BME) Employees in the Disciplinary Process in a National Health Service (NHS) Trust, Doctoral thesis, University of Surrey, Guildford, available at: http://epubs.surrey.ac.uk/808709/ (accessed 19 June 2020).

Sennett, R. (2009), The Craftsman, Penguin, London. ISBN: 9780141048468.

Seukwa, L.H. (2007), The Ingrained Art of Survival: the Nexus between Competence and Migration as Reflected in Refugee Biographies, Rüdiger Köppe Verlag, Köln. ISBN-13: 978-3896452504

Skeggs, B. (2004), Class, self, culture, Routledge, London and New York. ISBN: 0415-30086-X

Tascon S. and Gatwiri, K. (2020), 'Towards Cultural Humility: Theorising Cultural Competence as Institutionalised Whiteness', Social Work \& Policy Studies: Social Justice, Practice and Theory, Vol. 3 No. 1, pp.1-16, available at:

https://openjournals.library.sydney.edu.au/index.php/SWPS/article/view/14406/1284 $\underline{5}$ (accessed 23 June 2020)

Thackrah, R.D. and Thompson, S.C. (2013), 'Refining the concept of cultural competence: building on decades of progress', Medical Journal of Australia, Vol. 199 No.1: pp.35-38. DOI: 10.5694/mja13.10499

Traynor, M. et al. (2013), 'Disciplinary processes and the management of poor performance among UK nurses: bad apple or systemic failure? A scoping study, Nursing Inquiry, Vol. 21 No.1, pp.51-58. DOI: 10.111/nin.12025

Tsing, A. L. (2019), The Mushroom at the End of the World: on the Possibility of Life in Capitalist Ruins, Princeton University Press, Princeton and Oxford. ISBN: 978-0- 
$691-17832-5$

Tuwahi Smith, L. (2012) Decolonising Methodologies: Research and Indigneous Peoples, second edition, Zed Books, London, NY. ISBN: 978-1848139503

Winddance Twine, F. and Gallagher, C. (2008), 'The future of whiteness: a map of the "third wave"', Ethnic and Racial Studies, Vol. 31 No. 1, pp. 4-24. DOI: $10.1080 / 01419870701538836$

Wrede, S. (2010), 'Nursing: globalisation of a female-gendered profession', Kuhlmann, E. and Annandale, E. (Ed.s) The Palgrave Handbook of Gender and Healthcare, Palgrave Macmillan, Basingstoke. ISBN: 978-1-137-01514-3 